\title{
Skinner: Sobre Ciência e Comportamento Humano ${ }^{1}$
}

Skinner: On science and human behavior

Angelo Augusto Silva Sampaio

Universidade Federal da Bahia

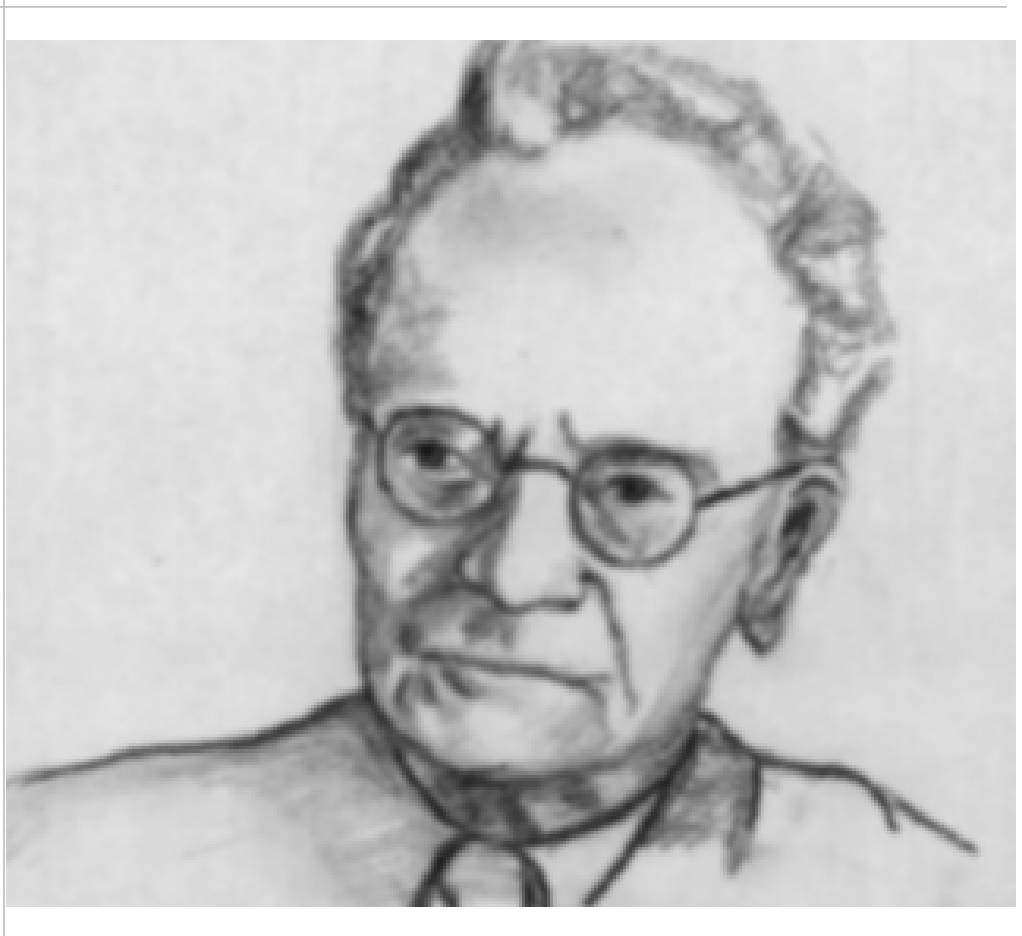




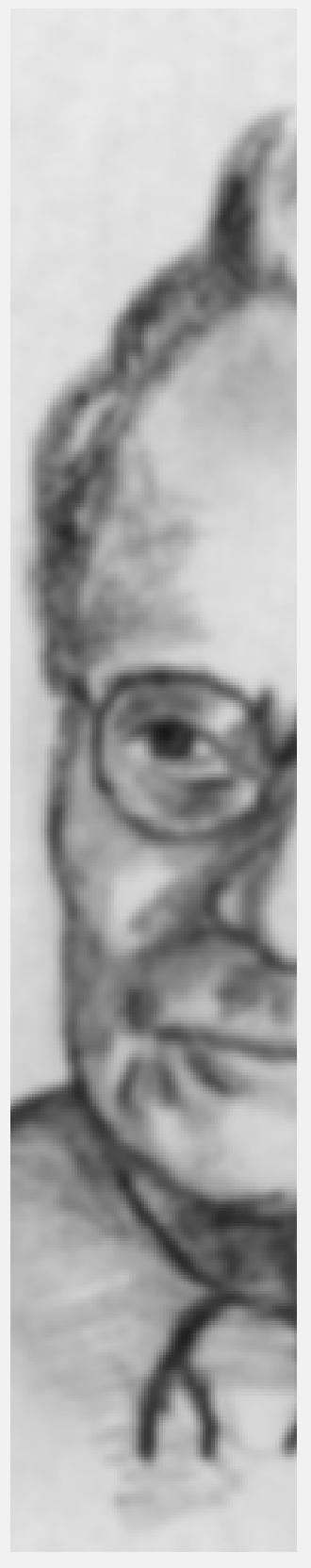

Resumo: Atualmente, não se pode pensar no estudo do comportamento humano sem considerar a abordagem científica a este objeto: o campo da Psicologia científica. Esse campo é disputado por diversos enfoques teóricos que divergem quanto ao modo como definem ciência e comportamento humano. A abordagem de B. F. Skinner foi bastante proeminente no século $X X$, mas ainda continua a ser mal-entendida. Partindo do desenvolvimento histórico de sua obra, o presente texto visa a iluminar alguns aspectos relacionados às noções de ciência e comportamento humano desse autor e ressaltar as transformações por que passaram. Analisam-se três tópicos da obra de Skinner: seu período inicial (de 1930 a cerca de 1938), a obra "Ciência e Comportamento Humano" de 1953, e as influências da Biologia. São enfatizados aspectos relevantes da sua teorização sobre o tema: busca por relações funcionais, ênfase nos dados empíricos, operacionismo, externalismo, multideterminação do comportamento, experimentalismo, previsão e controle, ética.

Palavras-chave: Skinner, B. F., comportamentalismo, ciência, comportamento.

Abstract: No one can think about the study of human behavior nowadays without considering the scientific approach to this object: the field of scientific Psychology. This subject is disputed by many theories that diverge on the way they define science and human behavior. B. F. Skinner's approach was very prominent in the 20th century, but still remains misunderstood. Starting from the historical development of his work, the present paper aims to shed some light in aspects related to this author's notions of science and human behavior and highlight transformations that undertook them. Three topics of Skinner's work are analyzed: its initial period (from 1930 to about 1938), the book "Science and Human Behavior", published in1953, and the influences from Biology. Relevant aspects of his theorization about the theme are stressed: the search for functional relations, focus on empirical data, operationism, externalism, behavior multidetermination, experimentalism, prediction and control, ethics.

Key words: Skinner, B. F., behaviorism, science, behavior.

Em dezembro de 1879, na Universidade de Leipzig, Alemanha, Wilhelm Wundt fundou o primeiro laboratório de Psicologia do mundo. Esse fato é saudado por alguns como o momento de confirmação da independência da Psicologia em relação à Filosofia - seria mesmo a fundação da Psicologia moderna (Schultz; Schultz, 2000). Parece-nos, entretanto, mais apropriado (ou mais preciso) tratá-lo como um marco - mais simbólico do que propriamente histórico - do avanço da ciência sobre um "novo" campo de estudos: aquele da ação humana. Especificamente, ele reflete um processo de aplicação de técnicas que vinham sendo desenvolvidas pela Fisiologia da época a questões que, por séculos, ocuparam filósofos: a natureza da consciência e de seus processos, a percepção, a sensação,
1-O autor agradece imensamente a Milena $S$. Lisboa, por sua paciência e seu amor, e a Rodrigo P. Guimarães, por seu incentivo $e$ seus comentários. 
as emoções - os processos psicológicos, enfim. A fundação do primeiro laboratório de Psicologia, assim, assinala o início de uma ampla redefinição do modo de se estudar aqueles fenômenos e do próprio significado de Psicologia. Antes explorados apenas pela especulação e partindo essencialmente de vivências cotidianas, aqueles fenômenos se convertem, agora, em objetos de estudo científico abordados pelo método experimental. Estaria fundada a Psicologia científica.

Desde fins do século XIX, desse modo, é praticamente impossível tratar-se do conhecimento sobre as ações humanas sem considerar a proposta de abordagem científica a esse objeto. Mesmo que se busque criticála, a referência à abordagem científica é onipresente. A própria delimitação/ regulamentação da atuação profissional do psicólogo, muitas vezes, se vale da referência a "critérios científicos" - vide, por exemplo, as inúmeras referências a eles no Código de Ética Profissional e em resoluções do Conselho Federal de Psicologia.

As noções de comportamento humano e de ciência, enfim, tornaram-se praticamente indissociáveis, e é justamente a partir desse momento que diversos projetos de conhecer cientificamente o comportamento humano começam a competir e que o que se entende por ciência e/ou como aplicá-la devidamente a esse campo passa a ser alvo de disputas dentro da nascente Psicologia científica.

Um momento fundamental nessa disputa pelo projeto dominante de Psicologia científica é a proposição, por Burrhus Frederic Skinner, do seu Comportamentalismo Radical. Chegando a ser considerado o psicólogo mais eminente do século XX (Haggbloom et al., 2002), Skinner marcou profundamente toda a Psicologia americana (e, em conseqüência, a Psicologia mundial) do século passado e continua ainda hoje a ser amplamente estudado, discutido e a ter suas proposições ampliadas e revisadas (por ex. Glenn, 1988; Malagodi, 1986 e Malott, 1988). Afora sua importância para a construção da Psicologia como a conhecemos hoje, um conhecimento mais aprofundado do discurso de Skinner é também fundamental para evitar (ou buscar remediar) um conjunto de mal-entendidos que cercam seu pensamento. É para os fundamentos filosóficos do comportamentalismo radical, assim, que este trabalho se voltará.

De início, "Pode-se dizer que as bases fundamentais que norteiam a obra de Skinner estão vinculadas a sua pretensão de fazer da Psicologia uma ciência e, para compreender essas bases filosóficas, precisamos identificar os modelos de ciência que ele adota." (Micheletto, 2001, p. 31). É assim que, para nos aproximarmos da abordagem comportamentalista radical definida pelo próprio Skinner (1974/1995a), inclusive, como a de uma filosofia da ciência buscaremos empreender uma análise da sua concepção de ciência, pilar essencial para a fundamentação de qualquer modo dito científico de encarar o homem e o seu comportamento. Indissociável desse objetivo, aparece como essencial também a discussão da sua concepção de comportamento humano. Dessa forma, buscaremos assinalar algumas influências e transformações por que passaram tais concepções (e outras relacionadas: causalidade, explicação, etc.) no desenvolvimento da obra de Skinner.

Para tanto, trataremos de três tópicos principais: o período inicial de publicação em Psicologia de Skinner (compreendendo, aproximadamente, os anos de 1930-38) e as influências da Física; a obra Ciência e Comportamento Humano (Skinner, 1953/1970), e, por fim, as influências da Biologia sobre seu pensamento.

\section{As transformações do pensamento de Skinner}

Desde suas primeiras publicações, em 1930, até "Can Psychology be a science of mind?" 
(Skinner, 1990), artigo completado na véspera de sua morte, Skinner desenvolveu uma verdadeira visão de mundo (Michael, 1980), que aborda as mais diversas questões (ética, educação, organização social, cultura etc.) de um ponto de vista muito particular. Essa extensa obra, como qualquer outra de seu porte, é perpassada por aspectos unificadores, mas também por transformações.

Por um lado, pode-se afirmar que toda a sua obra é marcada por alguns pontos gerais que parecem permanecer inalterados:

o estabelecimento do objeto de estudo - o comportamento; a suposição do comportamento como determinado; a pretensão de fazer uma análise científica do comportamento a partir da noção de ciência proposta pela ciência natural; o estudo realizado a partir do dado empírico; o afastamento de toda metafísica do saber científico; a proposta de previsão e controle (Micheletto, 2001, p. 30).

Essas marcas, por outro lado, além de muito genéricas, tiveram seu sentido alterado ao longo da obra de Skinner. Como esperamos demonstrar no decorrer deste texto, ao menos dois grandes momentos podem ser distinguidos nesse processo. Por um lado, um período inicial englobando aproximadamente os anos de 1930-38, em que o autor, como ele próprio admitiria depois (Skinner, 1989/1995b, p. 176), ainda "estava comprometido em demasia com o 'reflexo'" em termos da sua noção de comportamento (apesar de as suas investigações o terem conduzido à formulação do conceito de operante ainda em 1937) e onde a influência de uma concepção de ciência adotada pela Física era proeminente. Por outro lado, em um período posterior, em que seu foco de interesse recai mais sobre o comportamento operante, suas concepções vão gradualmente amadurecendo e sua noção de ciência passa a ser mais marcadamente influenciada pelas noções da Biologia. Esses dois momentos, entretanto, se imbricam no desenvolvimento da obra skinneriana: pode-se perceber a presença de certas concepções do período inicial nos escritos posteriores de Skinner e interpretar algumas mudanças de concepção como um desenvolvimento do próprio pensamento do autor.

Essas alterações, em alguns dos fundamentos filosóficos da sua visão de mundo, podem ser responsáveis, porém, por parte das interpretações errôneas do comportamentalismo radical. É para uma breve análise dessas transformações no pensamento de Skinner que agora nos voltamos.

\section{0-1938: o período inicial e as influências da física}

A adesão de Skinner ao comportamentalismo e seu conseqüente ingresso na pós-graduação em Psicologia de Harvard (em 1928) podem ser atribuídos, em grande parte, a sua leitura do livro "Behaviorism", de John B. Watson (Skinner, 1989/1995b). De fato, podemos admitir, com o próprio Skinner, que, desde o início, a sua concepção de Psicologia, de estudo do comportamento, era muito semelhante àquela proposta por Watson em seu famoso artigo de 1913: "Segundo o ponto de vista comportamentalista, a Psicologia é um ramo puramente objetivo e experimental da ciência natural. Seu objetivo teórico é a predição e o controle do comportamento" (citada por Skinner, 1989/1995b, p. 165). Foram as aspirações de uma ciência do comportamento voltada para a previsão e o controle que o motivaram a ingressar na Psicologia. Assim, desde o princípio, Skinner pretendia levar a cabo uma análise científica do comportamento a partir de uma noção de ciência fortemente inspirada nas ciências naturais (Micheletto, 2001). Cabe assinalar, entretanto, quais seriam, mais especificamente, as principais influências que convergiram para moldar a forma como ele empreenderia essa aspiração.

O modelo de ciência que inicialmente vai influenciar Skinner é aquele associado às
"O estabelecimento do objeto de estudo - o comportamento; a suposição do comportamento como determinado; a pretensão de fazer uma análise científica do comportamento a partir da noção de ciência proposta pela ciência natural; o estudo realizado a partir do dado empírico: o afastamento de toda metafísica do saber científico; a proposta de previsão e controle"

Micheletto 
Para Ernst Mach, o avanço da Física dependia do afastamento de concepções metafísicas pressupostas na elaboração de muitos dos conceitos dessa disciplina Micheletto transformações por que a Física passava no final do século XIX e início do século XX e às críticas que, nessa época, se levantavam contra o modelo mecanicista fundado na Física newtoniana (Micheletto, 2001). O modelo mecanicista explicava os eventos do mundo em termos da ação causal de forças diversas, no tempo e no espaço, sobre a matéria. Cada coisa se moveria devido à interação mecânica com outras coisas, todas sujeitas a um conjunto de forças. Nesse modelo, além disso, considerava-se que a realidade possuísse existência independente do sujeito que a experiencia e o princípio de explicação dessa realidade deveria ser sempre baseado em um mecanismo. Foram essas noções que acabaram por levar à elaboração de conceitos especulativos, interpretativos ou até metafísicos na busca por tais explicações sempre baseadas em mecanismos.

Esse modelo começa a ser criticado, já no final do século XIX, por dois importantes autores, citados logo nas primeiras obras de Skinner: os físicos Ernst Mach e Percy Bridgman.

\section{Ernst Mach (1838-1916)}

Para Ernst Mach, o avanço da Física dependia do afastamento de concepções metafísicas pressupostas na elaboração de muitos dos conceitos dessa disciplina (Micheletto, 2001). O caminho para tanto seria a construção de um conhecimento firmemente baseado em observações empíricas. Segundo ele, a suposição da existência de um mundo "real", externo ao sujeito, não poderia ser sustentada, já que só teríamos acesso às nossas sensações - seria a partir da análise apenas dessas sensações, assim, que construiríamos nosso conhecimento do mundo. Essas noções colocam a questão da existência real das coisas (tão fundamental para o modelo mecanicista) simplesmente como algo sem significado - já que não passível de ser resolvida em definitivo. "Mach torna sem significado tudo o que não produza resultado que possa referir-se à sensibilidade" (Micheletto, 2001, p. 32). Para esse autor, em conseqüência, a noção de explicação (tradicionalmente associada à de causalidade mecânica) acaba por igualar-se à de descrição de relações ordenadas entre sensações, entre fatos observados. Abandonase a noção de causa e efeito, de causalidade mecânica. Tudo o que seríamos capazes de dizer sobre qualquer aspecto do mundo é que freqüentemente tivemos certas sensações que foram freqüentemente seguidas por outras.

As concepções de Ernst Mach têm sido analisadas (de ângulos por vezes um pouco distintos) por diversos comportamentalistas contemporâneos. Baum (1999, cap. 2), por exemplo, ao tratar Mach como um pragmatista, ressalta que a amizade desse autor com William James seria a responsável pela influência do pragmatismo sobre o comportamentalismo radical. Segundo Baum (1999, cap. 2), a noção de ciência de Skinner (não só no período inicial de sua obra) e do comportamentalismo radical como um todo seria a mesma de Mach e James: a busca por descrições econômicas, eficientes e as mais abrangentes possíveis da experiência humana com o mundo natural. Os conceitos científicos nos permitiriam passar adiante, de uma maneira econômica, nossas experiências com determinados aspectos da natureza. Os conceitos científicos seriam o modo encontrado pelos cientistas para falar de maneira breve, e, em conseqüência, de maneira mais eficiente, de um grande conjunto de experiências. É nesse sentido que a distinção entre "descoberta" e "invenção" seria sem sentido. O que normalmente é chamado de "descoberta de um novo fenômeno" seria mais uma forma criativa e resumida que alguém inventou para falar sobre nossas experiências do que alguma forma de representar um aspecto novo da realidade.

Mach, por outro lado, pode ser interpretado como um positivista influenciado pelo pensamento darwinista se ressaltarmos como, para ele, a ciência seria um discurso privilegiado sobre a realidade (Tourinho, 2003). Apesar da continuidade entre o conhecimento comum e 
o da ciência - que Mach destaca - esta última ainda incorporaria de maneira mais eficiente um princípio de economia, organizando, de modo mais produtivo, a experiência. Sua noção de verdade, entretanto, o distanciaria um pouco da tradição positivista. Para Mach, a "verdade era uma questão de promoção da adaptação de um indivíduo ou da espécie ao ambiente circundante" (Smith, 1989, p. 272, apud Tourinho, 2003, p. 33), o que descarta qualquer concepção de universalidade das afirmações científicas.

\section{Percy Bridgman (1882-1961)}

Bridgman também parte de uma crítica às noções mecanicistas de realidade e de causalidade para desenvolver seus conceitos sobre a prática científica. Esse autor, na obra que será citada por Skinner em seus trabalhos (Bridgman, 1928), critica o modo como Newton definia conceitos como os de tempo, massa e comprimento a partir de propriedades não-naturais, não verificáveis empiricamente (Tourinho, 1987). Para Bridgman, os conceitos deveriam resumir-se à descrição dos tipos de procedimento (operações) que foram utilizados para o estudo do fenômeno a que se referem (Micheleto, 2001). O conceito de comprimento, por exemplo, não deveria ser entendido como uma propriedade intrínseca das coisas, mas como sinônimo do conjunto de ações realizadas para chegar-se ao número que chamamos de comprimento das coisas. Essas noções, associadas ao movimento operacionista, tiveram uma grande influência sobre os psicólogos de Harvard por volta dos anos trinta, aí incluído Skinner - que, já em 1930, na sua tese de doutorado, tentava aplicálas à análise do conceito de reflexo.

\section{Os primeiros trabalhos de Skinner}

Na sua tese de doutorado, defendida em $1930^{3}$, e em alguns trabalhos posteriores (ao menos até 1937), Skinner busca realizar uma análise científica do comportamento a partir do conceito de reflexo - um objeto de estudo que Ihe permitia observar e controlar as variáveis ambientais que o determinavam e elaborar previsões (Micheletto, 2001). Na sua tese, Skinner empreende uma revisão histórica do conceito (como já haviam feito Mach e Bridgman com os conceitos da Física) e acaba por defini-lo (operacionalmente, como advogado por Bridgman) como uma correlação observada entre um estímulo e uma resposta. O modo como, em sua tese e nesse período inicial, Skinner busca estabelecer sua ciência do comportamento o aproxima bastante das transformações que vinham ocorrendo na Física da época. Como Micheletto (2001) ressalta:

[No conceito de reflexo de Skinner] Essa delimitação da correlação a eventos observados nos extremos da série estímulo e resposta afasta a análise do comportamento do interesse pela mediação de estruturas localizadas no sistema nervoso. A crítica de Mach e Bridgman aos supostos mecanicistas de um meio necessário à propagação ou condução de efeitos causais pode ser relacionada à não consideração de estruturas mediadoras na análise do comportamento (p. 33).

Skinner também se aproxima das propostas críticas ao mecanicismo na Física no que tange a: 1) sua definição operacional do conceito de reflexo; 2) uma noção de explicação que a iguala à de descrição, e 3) o abandono da noção de causalidade mecânica e a ênfase sobre o estabelecimento de relações funcionais entre eventos observados. Como o próprio Skinner afirmou, referindo-se ao início de sua carreira: "meu compromisso era com o empiricismo de Ernst Mach" (Skinner, 1989/1995c, p.149).

A noção de ciência que parece guiar os primeiros trabalhos de Skinner, assim, deve muito a Mach e a Bridgman. A ênfase sobre o empírico e sobre as experiências concretas vivenciadas pelo cientista, a afirmação da indissociabilidade entre as operações
3 "The concept of the reflex in the description of behavior" " $O$ conceito do reflexo na descrição do comportamento") 
Por fim, vale ressaltar que, apesar da influência da Biologia sobre suas concepções de ciência e comportamento só aparecer mais marcadamente no período final de sua obra, desde essa época Skinner se refere à importância dessa disciplina na sua formação intelectual.
4 "O Comportamento dos Organismos: uma Análise Experimental". empregadas na investigação e o conhecimento obtido e a sustentação da ciência como discurso mais eficiente: todas essas noções presentes no pensamento skinneriano devem muito à influência dos dois físicos.

Nesse período inicial, também devem ser ressaltados ao menos dois aspectos do pensamento skinneriano que viriam a ser bastante modificados (Micheletto, 2001). Em primeiro lugar, Skinner ainda supõe que, na análise do comportamento, deve-se buscar estabelecer uma relação do comportamento com algum evento anterior - que provocaria aquela determinada resposta. Isso parece estar associado, ainda, a um demasiado comprometimento com o conceito de reflexo (reconhecido, mais tarde, pelo próprio Skinner [Skinner, 1989/1995b]). Em segundo lugar, o pensamento de Skinner aparece, nessa época, ainda fortemente associado a um "suposto atomizador". As ações humanas, aí incluídas as mais complexas, seriam todas constituídas por partes menores (os reflexos); estas deveriam ser detectadas e compreendidas, e deveriam ser elaboradas leis que descrevessem a combinação dessas partes. Essa visão molecular do comportamento, além de acarretar uma simplificação, acaba por postergar o estudo de processos mais complexos do comportamento ou por minimizar sua importância.

É fundamental notar, ainda, que muitas concepções ou foram abandonadas ou sofreram alterações já durante o decorrer desse período. Em 1935, por exemplo, Skinner abandona a hipótese de que o questionamento da relação entre o conhecimento e o real seria sem sentido (o que o afasta de Mach e Bridgman) (Micheletto, 2001). Skinner passa a entender o processo do conhecer como fruto da relação entre uma realidade independente e um sujeito ativo que opera sobre ela a partir dos seus procedimentos de investigação (com seus respectivos limites e possibilidades). Em 1937, além disso, com a elaboração do conceito de operante, ele descarta a necessidade de, para qualquer ação, identificar-se um evento antecedente que a provoque. Como o próprio Skinner coloca:

A ação de um estímulo em 'eliciar' uma resposta era um bom exemplo de controle, e vários comportamentalistas permaneceram comprometidos com alguma versão do esquema estímulo-resposta por muitos anos; mas, de acordo com meus experimentos, o que acontecia depois que um organismo se comportava desempenhava um papel muito mais importante do que o que acontecia antes (Skinner, 1989/1995b, p. 176, grifo do autor).

Por fim, vale ressaltar que, apesar da influência da Biologia sobre suas concepções de ciência e comportamento só aparecer mais marcadamente no período final de sua obra, desde essa época Skinner se refere à importância dessa disciplina na sua formação intelectual. O fato de seu doutoramento ter sido associado, além do departamento de Psicologia, também ao de Fisiologia aponta isso. A influência das idéias do biofisiologista Jacques Loeb, além do mais, é vastamente reconhecida (Hackenberg, 1995), inclusive pelo próprio Skinner (1989/1995b), que, ao tratar das fontes do seu livro The Behavior of Organisms: an Experimental Analysis ${ }^{4}$, comenta: "Eu queria estudar o comportamento de um organismo absolutamente sem qualquer referência à vida mental, e isso era Watson; eu também desejava evitar referências ao sistema nervoso, e isso era Jacques Loeb", e, logo em seguida: "em Harvard eu fui para os laboratórios biológicos de W. J. Crozier - o principal discípulo de Loeb - para quem Loeb dizia que tinha 'ojeriza ao sistema nervoso'" (p. 164).

\section{3: "ciência e comportamento humano"}

Seguindo o desenvolvimento da obra de Skinner, cabe questionar se, em 1953, com a publicação de Ciência e Comportamento Humano, suas concepções de ciência e comportamento 
humano teriam se diferenciado das de seu período inicial. Outras influências sobre o seu pensamento podem ser vislumbradas? Que outras concepções próprias podem ser aí destacadas?

Logo nas primeiras páginas do livro, na "Apresentação da edição brasileira", Skinner enfatiza a necessidade de o conhecimento ser útil e ter um significado prático. Para ele, a ciência poderia e deveria ser um "corretivo" para os problemas humanos (Skinner, 1953/ 1970, cap. I). Esse argumento é uma constante em toda a obra de Skinner. Suas principais justificativas para o empreendimento de uma ciência do comportamento humano são os resultados práticos para a sociedade - daí a ênfase na predição e no controle. Essa idéia nos serve para, primeiramente, ressaltarmos a importância da ciência para a sociedade no pensamento skinneriano.

Cabe indagar, porém, a que ciência ele se refere. Como essa ciência se realizaria, para Skinner? Quais seriam suas características?

\section{Sobre ciência}

Inicialmente, já no primeiro capítulo da obra, Skinner afirma que a ciência seria uma tentativa de descobrir ordem no mundo, de relacionar ordenadamente alguns acontecimentos com outros. A busca de ordem, porém, não seria apenas o objetivo da ciência, seria também um pressuposto seu. Para se buscar relacionar ordenadamente acontecimentos do mundo, tem-se que, primeiro, supor que esses acontecimentos já sejam, de alguma forma, ordenadamente relacionados entre si.

Os objetivos da ciência seriam, assim, a descrição, a previsão e o controle. Note-se que Skinner não menciona a explicação como um dos objetivos da ciência - como muitos autores o fazem. Podemos atribuir essa atitude à noção machiana da equivalência entre descrição e explicação.
No segundo capítulo do livro (“Uma ciência do comportamento"), Skinner passa a discutir, de modo mais prolongado, as características da ciência como ele a entende. Logo no início, por exemplo, o autor comenta: "Como apontou George Sarton, a ciência é única ao mostrar um progresso acumulativo" (Skinner, 1953/ 1970, p.15, grifo nosso), isto é, para Skinner, os "resultados tangíveis e imediatos" da ciência poderiam ser comparados de modo a se mostrar, por exemplo, que a eficácia da ciência moderna é muito superior à da ciência grega. Esse caráter acumulativo, no entanto, não parece estar necessariamente associado a nenhuma idéia de aproximação inexorável da "verdade" ou de "desvelamento" de um mundo separado do sujeito conhecedor - próximas de uma posição positivista clássica. De acordo com as concepções de Mach e do pragmatismo - com as quais Skinner efetivamente mais se aproxima - a invenção de conceitos que tivessem por base novas experiências apenas equivaleria à adoção de ações mais adaptativas em relação a um ambiente historicamente determinado (por ex. Baum, 1999; Tourinho, 1996), ou seja, se alguma noção de verdade for atribuída a Skinner, a definição mais razoável seria a de verdade como efetividade no agir sobre o mundo. De fato, mais para o fim do capítulo, o próprio Skinner, citando Mach, caracteriza a ciência como a busca de um agir mais eficiente no mundo.

Em seguida, Skinner comenta que a ciência produz "acumulações organizadas de informação". O que lemos, quando estudamos física, química ou biologia, seriam bons exemplos de tais "acumulações". Ele ressalta, no entanto, que não podemos tomar a presença desses resultados específicos da ciência (conceitos, leis e teorias da Física, da Química ou da Biologia) em outros campos do saber como indicadores fidedignos de que também aí se utilizou o mesmo processo científico de investigação. "Essas acumulações não são a ciência mesma, mas os produtos da ciência" (Skinner, 1953/1970, p. 15), isto é, se a ciência 
deve visar, sim, à produção de tais acumulações organizadas de informação - o que também nos remete à noção de economia conceitual de Mach - a importação de conceitos de outras disciplinas científicas não pode ser tomada como garantia de cientificidade.

Logo a seguir, o autor cita alguns outros aspectos comuns a diversas ciências e importantes para a prática científica, mas que não poderiam ser tomados como características definidoras, essenciais, da ciência: a medida exata, o cálculo matemático e uso de instrumentos (aparelhos de pesquisa ou instrumentos matemáticos).

Desses comentários, podemos começar a construir uma imagem da prática científica como um empreendimento singular, acumulativo e capaz de dar conta de todos os fenômenos naturais a partir da mesma abordagem. Essa última idéia - a de que uma mesma abordagem pode dar conta da totalidade dos fenômenos naturais - porém, não deve ser entendida como uma recomendação para o uso dos mesmos métodos - e muito menos dos mesmos conceitos - em todas as disciplinas. As características essenciais da ciência para Skinner, e que deveriam, estas sim, ser adotadas para o estudo de qualquer assunto, não são determinados conceitos, instrumentos ou métodos rígidos, mas, sim, atitudes. Como o próprio Skinner (1953/1970) comenta: "A ciência é, antes de tudo, um conjunto de atitudes" (p. 15). Estas poderiam ser resumidas nas três seguintes:

a ênfase nos fatos, nos dados, no empírico - o que deveria levar à rejeição da autoridade e dos desejos do pesquisador quando estes interferem no contato com a natureza;

- a honestidade intelectual - ressaltada também por Bridgman (que Skinner cita neste ponto);

- e o afastamento de conclusões prematuras. Mais à frente, em outros capítulos, o autor continua a enumerar outras características da sua concepção de ciência. Skinner cita o abandono do conceito de "relação de causa e efeito" em favor do de "relação funcional". Para ele, a ciência estudaria mudanças nas variáveis independentes e dependentes. Os novos termos, continua, não sugerem como uma causa produz um efeito. Nesse ponto, parece novamente clara a influência de Mach.

\section{O estudo científico do comportamento humano}

Uma compreensão mais clara da noção de ciência desenvolvida por Skinner nessa obra pode ser obtida a partir das suas concepções sobre o estudo (científico) do comportamento humano.

Ao tratar do tema, Skinner começa enfatizando a extrema complexidade desse objeto de estudo. Ressalta que essa é uma das objeções normalmente levantadas contra a possibilidade de uma ciência do comportamento e descartaa por considerar que: 1) "da complexidade não se segue a autodeterminação" (Skinner, 1953/ 1970, p. 20); 2) nada se pode afirmar sobre os limites das investigações desse objeto até que tenhamos tentado, e, mais importante, 3) podese simplificar as condições em laboratório ou através de análises estatísticas. A importância das técnicas experimentais e matemáticas para o estudo do comportamento (mesmo sem serem consideradas essenciais), aqui novamente ressaltadas pelo autor, deve ser marcada como uma das características do seu pensamento. $\mathrm{O}$ estabelecimento de relações quantitativas entre as variáveis em estudo, obtidas após um adequado controle das condições experimentais, parece ser a via privilegiada de descrição científica para Skinner. No estudo das variáveis que controlam o modo como os organismos se comportam, assim, "qualquer condição ou evento que tenha algum efeito demonstrável sobre o comportamento deve ser considerada" (Skinner, 1953/1970, p. 21). Essas 
condições (ou eventos) deveriam ser descobertas e analisadas, preferencialmente, de forma quantitativa.

Tendo delimitado o tipo de análise que a ciência deveria empreender, o autor passa a especificar mais claramente quais seriam as variáveis das quais o comportamento é função. As variáveis a serem consideradas deveriam ser aquelas ao alcance de uma análise científica, aquelas que

estão fora do organismo, em seu ambiente imediato e em sua história ambiental. [Aquelas que] Possuem um status físico para o qual as técnicas usuais da ciência são adequadas e permitem uma explicação do comportamento nos moldes da de outros objetos explicados pelas respectivas ciências (Skinner, 1953/1970, p. 26, grifo do autor).

E quanto às variáveis ou condições internas (tanto psicológicas quanto fisiológicas)? Qual o seu papel numa ciência do comportamento? Essa é uma questão fundamental e recorrente na obra de Skinner. Lembremos que uma de suas convicções ao começar a estudar o comportamento, já na década de 1930, era estudar o comportamento do organismo como um todo, sem recorrer a estruturas fisiológicas ou psicológicas mediadoras. Vamos alongar-nos um pouco nesse ponto, tratando do modo como o autor lida com ele em 1953.

Seu argumento parte da afirmação de que a relação do organismo com o ambiente pode ser entendida como o encadeamento causal de três elos: uma operação externa ao organismo (por ex., privação de água), uma condição interna (por ex., sede fisiológica ou psicológica) e uma resposta (por ex., beber água). Assim, teoricamente, poderíamos prever o terceiro elo a partir do segundo. Lidar com as condições internas do organismo (que precedem imediatamente ao comportamento) seria inclusive preferível, do ponto de vista da previsão e do controle, por ser essa uma variável temporalmente próxima. O problema com esse tipo de variável é que não temos ainda como obter dados independentes e confiáveis sobre ela. Daí, que, em geral, infere-se o segundo elo ou do primeiro ou do terceiro. Para o autor, esse é o método mais censurável, tanto prática quanto teoricamente.

Mesmo que conseguíssemos contornar tal problema e manipular com segurança as condições internas que precedem imediatamente o comportamento, porém, "ainda teríamos de lidar diretamente com aquelas enormes áreas do comportamento humano controladas através da manipulação do primeiro elo" (Skinner, 1953/1970, p. 28). Sua conclusão é que "A objeção aos estados interiores não é a de que eles não existem, mas a de que não são relevantes para uma análise funcional" (p.28). As informações sobre o segundo elo dessa cadeia podem esclarecer a relação entre os outros dois elos - que é, esta sim, útil para a previsão e o controle mas não podem alterar essa relação.

Em suma, em Ciência e Comportamento Humano, delineia-se uma concepção mais completa de ciência, que apresenta diversas continuidades com as noções do período inicial. A adesão a definições operacionais e a uma concepção de explicação que a iguala à de descrição de relações funcionais entre variáveis permanece como uma herança já daquele período. Skinner também parece manter uma concepção da ciência como um modo de produção de conhecimento que não se restringiria a alguns objetos de estudo, que abarcaria tanto a Física quanto a Biologia e a Psicologia, por exemplo. O que aparece de novo em 1953 é a afirmação mais clara da ciência como meio privilegiado de intervenção na realidade, de resolução de problemas sociais. Uma ciência do comportamento seria uma necessidade para a solução dos problemas sociais - e tiraria daí uma de suas principais justificativas.

Aqui, Skinner também aborda mais especificamente o comportamento humano, e
Emsuma, em

Ciência e Comportamento Humano, delineiase uma concepção mais completa de ciência, que apresenta diversas continuidades com as noções do período inicial. 
aí podemos ver todo um campo de discussão que, pelo menos, não era explícito no início da sua carreira. Um conjunto de concepções próprias utilizadas na abordagem desse objeto torna-se aqui de grande importância: o conceito de comportamento operante é amplamente utilizado e chega a ser predominante no livro; as análises que utilizam o conceito de comportamento verbal também são abundantes; a importância do comportamento social para as ações humanas é destacada (toda uma seção do livro - "O comportamento de pessoas em grupo" - é dedicada ao assunto), e as questões relativas à descrição, evolução e planejamento de culturas ocupam outra grande parte do livro. Skinner ressalta, além do mais, a extrema complexidade desse objeto de estudo - afirmação tantas vezes omitida por seus críticos - e sugere, para lidar com isso, a simplificação experimental das condições envolvidas. Vale a pena notar que, apesar de a ciência do comportamento a que Skinner se refere durante todo o livro ser a Análise Experimental do Comportamento, suas interpretações e comentários extrapolam grandemente o escopo das investigações produzidas nesse âmbito.

\section{As influências da biologia e os pontos fundamentais da proposta skinneriana sobre a ciência e o comportamento}

5 "A análise operacional de termos psicológicos".

6 Entendida como "a aplicação de princípios cientificamente compro vados como efetivos (na investigação de fenômenos menos complexos) a assuntos mais complexos, sobre os quais o conhecimento existente não e suficiente para tornar a previsão e o controle possiveis" (Tourinho, 1987).

7 Ou descoberta, de acordo com a discussão de Mach (vide subtópico acima).
Um segundo momento que podemos destacar é aquele em que Skinner explicita mais claramente as diferenças entre o seu projeto de ciência e os dos outros comportamentalismos, com a publicação do artigo "The operational analysis of psychological terms", ${ }^{5}$ em 1945 (Tourinho, 1987). É aí que fica bem marcada sua oposição a uma concepção de verdade por consenso público (acatada pelo comportamentalismo metodológico). A aceitação de um fenômeno ou de um conceito por uma ciência do comportamento não é mais vinculada a sua acessibilidade a pelo menos duas pessoas; o fundamental passa a ser se o cientista pode operar eficazmente com ele - trata-se de um critério mais instrumental, pragmatista (Tourinho, 1987). A interpretação ${ }^{6}$ é postulada como um método legítimo da ciência. É ainda naquele mesmo artigo (de 1945) que Skinner, como uma derivação dessa sua concepção de verdade, deixa claro que os eventos privados (conjunto de eventos e comportamentos que ocorrem sob a pele do indivíduo) incluem-se como objetos legítimos de estudo de uma ciência do comportamento.

Um terceiro momento significativo no processo de ampliação do seu objeto de estudo envolve a incorporação do comportamento verbal e da importância do ambiente social para o estudo do fazer humano - que pode ser simbolicamente marcado pelo lançamento do livro "O Comportamento Verbal" (Skinner, 1957/1978), mas que já se encontra presente ao menos desde 1953 (Skinner, 1953/1970). É aí que toda uma ampla gama de aspectos da ação humana vai ser definitivamente abarcada pelo pensamento skinneriano: questões relativas à cultura, à moral, à dinâmica da própria comunidade científica, etc.

Paralelamente à expansão do objeto de estudo, vamos assistir também a uma ampliação das determinações do comportamento alegadas por Skinner. Partindo de uma determinação mais restrita e imediata logo no começo de sua obra (associada à sua ênfase inicial no conceito de reflexo), passando por uma ampliação com a invenção do conceito de operante (já presente 
em 1953), a concepção da determinação ambiental do comportamento vai acabar sendo definida (no período pós-1953) como resultado da interação entre as histórias filogenética (seleção natural), ontogenética (condicionamentos) e cultural (evolução cultural) do indivíduo.

Tais mudanças no modo de encarar a ação humana - expansão do objeto de estudo pertinente a uma ciência do comportamento e ampliação de suas determinações - podem ser entendidas como resultado de uma influência crescente da Biologia sobre o pensamento de Skinner. Segundo Micheletto (2001):

Esse novo significado dado ao fazer se vincula às influências das ciências biológicas, especificamente a teoria da evolução por seleção natural, que trazem para o comportamento um novo conjunto de pressupostos. As referências aos supostos da teoria da evolução por seleção natural começam a aparecer a partir da distinção entre reflexos respondentes e operantes. A vinculação com a seleção natural vai ficando cada vez mais explícita e abrangente. Se de início Skinner busca na seleção natural os princípios que orientam sua concepção de objeto, gradualmente esses princípios se estendem à própria noção de causalidade (p. 38).

Seriam ao menos quatro as características das espécies propostas por Charles Darwin que teriam contribuído para a noção skinneriana de comportamento (Micheletto, 2001): 1) elas não são imutáveis - ao contrário, são produtos momentâneos de um constante processo de transformação; 2) a variabilidade interna é uma condição essencial para a evolução, a seleção (sobrevivência) de variedades mais bem adaptadas ao ambiente; 3) essa seleção ocorre a partir da utilidade, da eficiência de uma variação em relação a um dado ambiente; 4) os organismos não podem ser entendidos isoladamente do ambiente em que vivem, aí incluídas suas relações com outros membros da espécie e com outras espécies distintas. São esses mesmos supostos básicos que encontramos na concepção de comportamento de Skinner, que o considera um objeto: 1) em constante transformação; 2) essencialmente variado (cada instância de comportamento, cada resposta particular, é única, não é igual a nenhuma outra); 3) que tem suas unidades selecionadas por sua eficiência em lidar com o mundo, e 4) que não pode ser entendido sem referência ao ambiente em que ocorre (genético, físico e social).

A influência das ciências biológicas também se estende à noção de causalidade adotada por Skinner após a elaboração do conceito de operante (Micheletto, 2001). A noção de seleção pelas conseqüências implicou, desde o início de seu uso por Skinner, um afastamento ainda maior de uma causalidade mecanicista do comportamento. Pelo menos dois importantes aspectos podem ser enumerados para confirmar tal assertiva: a seleção pelas conseqüências é uma forma de causalidade muito menos visível do que aquela da Física do século XIX (e muito mais complexa), e é uma forma de combater as noções metafísicas que se infiltraram na mecânica clássica e que orientaram concepções mentalistas de uma mente criadora (Micheletto, 2001). Vale lembrar que essa forma de causalidade foi estendida por Skinner aos três níveis de determinação do comportamento (filogênese, ontogênese e cultura) - todos explicados em termos selecionistas (Tourinho, 2003).

\section{Considerações finais}

Em suma, podemos perceber que, desde o início de sua obra, Skinner se alinha a concepções críticas ao mecanicismo. Isso o leva a abandonar desde cedo a necessidade de referir-se a mecanismos físicos para dar conta 
da relação entre as operações do ambiente e a ação humana (suas críticas vão dirigir-se especialmente a referências ao sistema nervoso, real ou hipotético). Seguindo as concepções de Mach e Bridgman, a causalidade mecânica é criticada e substituída pela busca de relações funcionais entre variáveis. Também o modo como os conceitos são definidos é proposto de forma a evitar os problemas do mecanicismo e a promover uma ênfase sobre os dados empíricos. O operacionismo de Bridgman leva Skinner a elaborar conceitos tendo sempre como base as operações práticas envolvidas na sua mensuração.

Além dos princípios da análise funcional e do operacionismo, é também fundamental para o seu recorte básico de abordagem à realidade, desde o início de sua obra, a adoção do externalismo. Para Skinner, as variáveis que deveriam ser consideradas nas relações funcionais envolvidas na ação humana seriam aquelas externas ao organismo em estudo, aquelas relativas a seu ambiente, variáveis essas que também deveriam ser passíveis de descrição pelas ciências naturais.

O objeto de estudo para o qual esse modo de investigação se volta - o comportamento ou a ação humana - é visto de modo cada vez mais complexo ao longo da obra de Skinner. Começando com estudos restritos aos reflexos e associados a uma causalidade limitada aos eventos anteriores mais imediatos, Skinner passa a investigar o comportamento operante, o comportamento verbal e social e mesmo práticas culturais mais amplas, baseando-se numa perspectiva selecionista e na multideterminação do humano. Em última instância, o objeto a que Skinner atribui a sua ciência do comportamento pode ser entendido como o resultado da inter-relação de processos seletivos operando em três níveis: filogenético (relativo à espécie), ontogenético (relativo ao indivíduo) e cultural (relativo à sociedade), um objeto que, dessa forma, só pode ser devidamente compreendido na sua singularidade e levando-se em consideração suas diversas relações e níveis de determinação.

Dada a extrema complexidade do comportamento humano, uma ciência que se volte para ele deve, segundo Skinner, valerse de algumas "ferramentas" que the facilite o contato com esse objeto. Nesse sentido, seriam importantes para a sua investigação:

- uma busca pelo controle e simplificação das condições envolvidas (que poderia ser entendida como uma preferência pela experimentação);

- uma busca por descrições quantitativas das relações funcionais, especialmente em termos de freqüência e probabilidade;

- atitudes de honestidade intelectual e cautela no estabelecimento de conclusões;

- a adoção da previsão e do controle como critérios últimos de validação do conhecimento.

Um último (e fundamental) ponto no que se refere à ciência do comportamento proposta por Skinner parece estritamente relacionado a um dos dilemas mais prementes de nossos dias: o da ética da investigação e da prática científica. Skinner sempre justificou (e lutou) por uma ciência do comportamento com base na crença de que ela poderia ajudar na resolução da maioria dos grandes problemas com que nossa cultura convive. Para ele, o sentido último do empreendimento de uma análise do comportamento não era teórico, mas prático: o objetivo final dessa ciência seria o de promover a sobrevivência da cultura (Dittrich, 2004). Os analistas do comportamento, assim, deveriam voltar-se sempre para o desenvolvimento de uma ciência e de uma profissão voltados para tal fim. 


\section{Angelo Augusto Silva Sampaio}

Graduando de psicologia pela Universidade Federal da Bahia (UFBA).

Av. Euclydes da cunha, 443, apt. 801, edf. Mansão wimbledon.

Graça. Salvador - ba, brasil. Cep: 40150-120. Tel: (71) 3247-

7150.

E-mail: angsampaio@uol.com.br.

BAUM, W. Compreender o Behaviorismo: Ciência, Comportamento e Cultura. Porto Alegre: Ed. Artes Médicas Sul, 1999.

BRIDGMAN, P. W. The Logic of Modern Physics. New York: The MacMillan Company, 1928.

DITTRICH, A. Behaviorismo Radical, Ética e Política: Aspectos Teóricos do Compromisso Social. Tese de Doutorado em Filosofia. Universidade Federal de São Carlos, São Carlos, 2004.

GLENN, S. S. Contingencies and Metacontingencies: toward a Synthesis of Behavior Analysis and Cultural Materialism. The Behavior Analyst, v. 11, n. 2, 1988, pp. 161-179.

HACKENBERG, T. D. Jacques Loeb, B. F. Skinner, and the Legacy of Prediction and Control. The Behavior Analyst, v. 18, n. 2, 1995, pp. 225-236.

HAGGBLOOM, S. J.; WARNICK, R.; WARNICK, J. E.; JONES, V. K.; YARBROUGH, G. L.; RUSSELL, T. M.; BORECKY, C. M.; MCGAHLEY, R.; POWELL, J. L.,III; BEAVERS, J.; MONTE, E. The most Eminent Twentieth Century Psychologists. Review of General Psychology, v. 6, 2002, pp. 139-152

MALAGODI, E. F. On Radicalizing Behaviorism: a Call for Cultural Analysis. The Behavior Analyst, v. 9, n. 1, 1986, pp. 1-17.

MALOTT, R. W. Rule-governed Behavior and Behavioral Anthropology. The Behavior Analyst, v. 11, n. 2, 1988, pp. 181-203.

MICHAEL, J. Flight from Behavior Analysis. The Behavior Analyst, v. 3, n. 2, 1980, pp. 1-22.

MICHELETTO, N. Bases Filosóficas do Behaviorismo Radical. In Banaco, R. A. (org.). Sobre Comportamento e Cognição: Aspectos Teóricos, Metodológicos e de Formação em Análise do Comportamento e

Terapia Cognitivista. Santo André, SP: ESETec, 2001, pp. 29-44.
SCHULTZ, D. P.; SCHULTZ, S. E. História da Psicologia Moderna. São Paulo: Cultrix, 2000

SKINNER, B. F. Behaviorism and Logical Positivism de Laurence Smith. In Questões Recentes na Análise Comportamental. Campinas, SP: Papirus, (1989), 1995c, pp. 145- 150.

Ciência e Comportamento Humano. Brasília: Ed. UnB/FUNBEC, (1953), 1970.

O Comportamento Verbal. São Paulo: Cultrix/ EDUSP, (1957), 1974.

Can Psychology Be a Science of Mind? American

Psychologist, v. 45, n. 11, 1990, pp. 1206-10.

1995a

. Sobre o Behaviorismo. São Paulo: Cultrix, (1974),

The Behavior of Organisms aos Cinqüenta Anos. In _. Questões Recentes na Análise Comportamental. Campinas, SP: Papirus, (1989), 1995b, pp. 163- 181.

TOURINHO, E. Z. Sobre o Surgimento do Behaviorismo Radical de Skinner. Psicologia, v. 13, n. 3, 1987, pp. 1-11.

Behaviorismo Radical, Representacionismo e

Pragmatismo. Temas em Psicologia, n. 2, 1996, pp. 41-56.

A Produção de Conhecimento em Psicologia: a Análise do Comportamento. Psicologia: Ciência e Profissão, v. 23, n. 2, 2003, pp.30-41.
Referências 